practice, and it is very important to know risk factors that attenuate its effect in the treatment of osteoporosis.

Objectives: The aim of this study was to identify risk factors for inadequate response to the treatment of osteoporosis by DMAb.

Methods: Sixty-six patients treated with DMAb were observed retrospectively for one year. The mean age was 74 years, women were $91 \%$ and 36 patients with RA were included.We measured BMDs at lumbar and hip by dual-energy X-ray absorptiometry (Hologic Discovery) at baseline and one year later. We evaluated the effects of age, body mass index (BMI), use of glucocorticoide (GC), previous treatment for osteoporosis, BMD at baseline, bone metabolic markers (BAP; bone alkaline phosphatase, uNTx; urinary N-telopeptide), serum $\mathrm{Ca}$ and $\mathrm{P}$ levels and the previous vertebral fractures for inadequate response to DMAb. We defined the cases who could not gain the increase of BMD over $2 \%$ at the lumbar vertebrae and $4 \%$ at the hip as inadequate responders by taking the measurement error into account.

Results: Dose of PSL was significantly high in non-responder at non-RA trochanter and RA lumbar BMD $(p=0.028,0.006)$. BAP was higher in nonresponder at RA lumbar BMD $(p=0.007)$. Urinary NTX was significantly low in non-responder at non-RA lumbar and RA trochanter BMD $(p=0.026,0.048)$. Previous treatment for osteoporosis was significantly high in non-responder at non-RA lumbar, total hip and trochanter BMD $(\mathrm{p}=0.026,0.022,0.003)$. Multivariate logistic analysis including age, BMI, dose of PSL, BMD at baseline, BAP, UNTX, $\mathrm{Ca}$ and $\mathrm{P}$ level as confounders revealed that dose of PSL was the significant risk factors for no-response at lumbar BMD (OR0.634, 95\% Cl 0.433-0.93, $\mathrm{p}=0.02$ ). Conclusions: Patients receiving GC might not gain an adequate response to the treatment by DMAb for osteoporosis. Reducing dose of GC or altanative treatment regimen might be necessary.

References:

[1] Kuroda T. et al. J Clin Densitom 15: 392-8, 2012.

[2] Bauer D.C. et al. JAMA 174: 1126-34, 2014.

Disclosure of Interest: None declared

DOI: 10.1136/annrheumdis-2017-eular.3684

\section{FRI0552 THE CORRELATION BETWEEN EROSION AND BONE MINERAL DENSITY IN PATIENTS WITH RHEUMATOID ARTHRITIS TREATED WITH DENOSUMAB AND BIOLOGIC DMARDS: A PROSPECTIVE COHORT STUDY}

K. Izumi, Y. Kaneko, T. Hasegawa, T. Takeuchi. Division of Rheumatology, Department of Internal Medicine, Keio University School of Medicine, Tokyo, Japan

Background: We have previously reported the efficacy of denosumab combined with biological DMARDs on radiographic progression in rheumatoid arthritis (RA). Objectives: The aim of this work was to reveal the relationship between the changes in structural joint damage and in bone mineral density (BMD) in patients with RA who were started on denosumab in addition to biologic DMARDs.

Methods: We prospectively evaluated erosion (ERO) and joint space narrowing (JSN) scores by the van der Heijde-modified Sharp method and T-scores of the lumbar spine (LS) and total hip (TH) by dual energy X-ray absorptiometry scans at baseline and 12 months in the RA patients who were started on denosumab (60 mg every 6 months) for osteoporosis in addition to biologic DMARDs. We compared the 12-month change in ERO or JSN scores ( $\triangle E R O ; \triangle J S N)$ with the change in T-scores of the LS or TH $(\Delta \mathrm{LS} ; \Delta \mathrm{TH})$.

Results: Twenty-two patients ( 1 man and 21 women) at the mean \pm SD age of $74.4 \pm 8.1$ at baseline were included in this study. The T-scores of the LS and TH at baseline were $-1.38 \pm 1.57$ and $-2.53 \pm 0.85$, respectively. $\triangle \mathrm{ERO}, \Delta \mathrm{JSN}, \Delta \mathrm{LS}$, and $\Delta \mathrm{TH}$ were $0.16 \pm 0.49,0.44 \pm 0.66,0.30 \pm 0.39$, and $0.20 \pm 0.42$, respectively. BMD was significantly increased from baseline to 12 months. There was a significant inverse correlation between the $\Delta E R O$ and the $\Delta T H(\rho=-0.473, P=0.03)$, while there was no correlation between the $\triangle E R O$ and the $\Delta L S(P=0.98)$ nor correlation between the $\triangle J S N$ and the $\Delta L S(P=0.57)$ or $\Delta T H(P=0.25)$.

Conclusions: The change in erosive joint damage of hands and feet showed a significant relationship with the change in femoral BMD in patients with RA treated with denosumab and biologic DMARDs. BMD was ameliorated along with erosion by denosumab combined with biologic DMARDs, and may be an indicator for joint destruction.

References:

[1] Hasegawa T, Kaneko Y, Izumi K, Takeuchi T. Efficacy of denosumab combined withbDMARDs on radiographic progression in rheumatoid arthritis. Joint Bone Spine.2016 Jun 28. pii: S1297-319X(16)30099-9.

Disclosure of Interest: None declared

DOI: 10.1136/annrheumdis-2017-eular.2829

\section{FRI0553 THE EFFICACY OF 2-YEARS DENOSUMAB TREATMENT FOR GLUCOCORTICOID-INDUCED OSTEOPOROSIS (GIOP)}

K. Akashi $^{1}$, K. Nishimura ${ }^{2}$, G. Kageyama ${ }^{3}$, S. Ichikawa ${ }^{1}$, T. Shirai ${ }^{1}$, Y. Yamamoto ${ }^{1}$, Y. Ichise ${ }^{1}$, H. Yamada ${ }^{1}$, I. Naka ${ }^{1}$, D. Waki ${ }^{1}$, T. Okano ${ }^{1}$ S. Takahashi ${ }^{1}$, Y. Ueda ${ }^{1}$, S. Sendo ${ }^{1}$, A. Onishi ${ }^{1}$, J. Saegusa ${ }^{1}$, A. Morinobu ${ }^{1}$. ${ }^{1}$ Department of Rheumatology and Clinical Immunology, Kobe University Hospital, Kobe, ${ }^{2}$ Department of Endocrinology and Rheumatology, Kurashiki
Central Hospital, Kurashiki; ${ }^{3}$ Department of Rheumatology, Hyogo Prefectual Amagasaki General Medical Center, Amagasaki, Japan

Background: Osteoporosis is one of the important adverse effects in the glucocorticoids treatment for the patients with rheumatoid arthritis (RA) and connective tissue diseases (CTDs). Although the usefulness of denosmab for primary osteoporosis has been well-established, the efficacy for GIOP remains unclear.

Objectives: This study aimed to clarify the therapeutic effects of denosumab for GIOP.

Methods: We evaluated bone mineral density (BMD) and serum markers of bone metabolism (BAP, NTx, TRACP-5b and P1NP) of patients who had been treated with over $5 \mathrm{mg}$ of predonisolone for RA and CTDs, and denosumab for GIOP, for two years in Kobe University Hospital. BMD and serum markers were evaluated every six months for 2 years from the baseline. The changes of those data from baseline were analyzed by Student's t test using GraphPad Prism 5 software and $\mathrm{p}<0.05$ was considered statistically significant.

Results: Number of the patients were 53 (male: 4 cases, female: 49 cases), and their characteristics at the beginning of denosumab treatment were as below; age: $64.19 \pm 12.0$ years old, dose of prednisolon: $10.59 \pm 9.97 \mathrm{mg} /$ day, BMD of lumber spine: $0.768 \pm 0.112 \mathrm{~g} / \mathrm{cm}^{3}$, T-score of lumber spine: $-2.28 \pm 1.01$, BMD of femoral neck: $0.540 \pm 0.085 \mathrm{~g} / \mathrm{cm}^{3}$, T-score of femoral neck: $-2.28 \pm 0.76$. After 2 -years denosumab treatment, T-scores of lumber spine $(0.54 \pm 0.39$ gain $)$ and femoral neck $(0.13 \pm 0.26$ gain) were significantly increased from baseline (Figure; mean \pm SEM. $\left.{ }^{*}: p<0.05\right)$. In addition, the serum markers of bone metabolism, both absorption and formation, were significantly suppressed with denosumab.
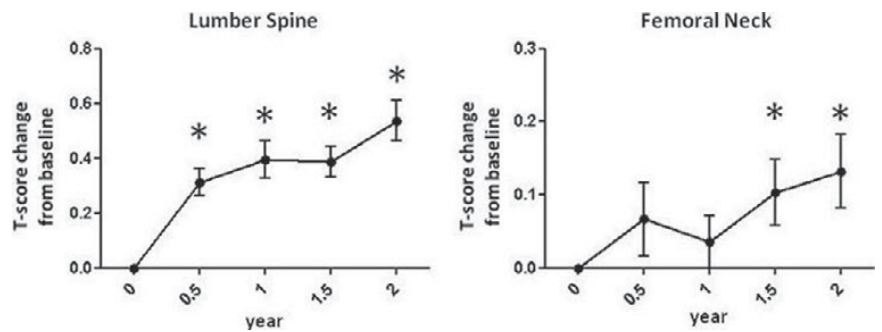

Conclusions: Denosumab can suppress bone metabolic turnover, and increase lumber spine and femoral neck T-scores of GIOP patients.

Disclosure of Interest: None declared

DOI: 10.1136/annrheumdis-2017-eular.3050

\section{FRI0554 NEW BIOMARKER FOR DIAGNOSIS OF OSTEOPOROSIS IN RHEUMATOID ARTHRITIS PATIENTS}

Y. Polyakova, L. Sivordova, Y. Akhverdyan, V. Kravtcov, B. Zavodovsky. Federal State Budgetary Institution "Research Institute of Clinical end Experimental Rheumatology", Volgograd, Russian Federation

Background: Bone mineral density and proteins/peptides determination in blood and urine as markers of bone resorption and formation are currently used to diagnose osteoporosis (OP) and metabolic bone diseases. However, these methods have some disadvantages for bone turnover evaluation. Recent evidence suggests that in RA changes in the secretion of hormones of white adipose tissue can be revealed [2]. One of them is Adiponectin possessing anti-inflammatory, anti-diabetic and anti-atherogenic properties [1]. Changes in Adiponectin levels may reflect influence of immune inflammation on bone turnover.

Objectives: To study the clinical and diagnostic value of serum Adiponectin determination in RA patients complicated by OP.

Methods: We examined 88 women with documented diagnosis of RA and mean disease duration of $6.56 \pm 0.88$ years. We used EULAR/ARA 2010 criteria to diagnose the patients. Female patients with II degree of disease activity (DAS28), Steinbrocker stage II (erosive), rheumatoid factor- and anti-cyclic-citrullinated peptide antibody-positive were prevalent. We excluded patients who had surgery or developed an infection within the last 8 weeks, pregnant and breast-feeding women, those with severe heart, liver or kidney disease, immune deficiency, leukopenia or chronic infection.

A control group of 45 healthy females aged of 25 and 59 years were included in the study. There were no reported findings of joint pain and RA symptoms in the group. The groups were adjusted for age $(p>0.05)$ and showed no statistically significant differences.

We measured serum Adiponectin levels $(\mu \mathrm{g} / \mathrm{ml})$ using Human Adiponectin ELISA commercial test systems. We plotted a curve using computer software. We diagnosed OP using dual-energy X-ray absorptiometry with LUNAR DPX PRO (GE, USA)

Results: Serum adiponectin levels in the control group were $12.5 \pm 0.9 \mu \mathrm{g} / \mathrm{ml}$ $(\mathrm{M} \pm \mathrm{m})$. Adiponectin levels in healthy subjects measured as $\mathrm{M} \pm 2 \mathrm{~d}$, ranged between 0.44 and $24.56 \mu \mathrm{g} / \mathrm{ml}$. Patients with OP and RA had significantly higher levels of serum Adiponectin $(p<0.001)$. Mean serum Adiponectin levels in RA patients who had normal bone density and had no OP were $35.21 \pm 0.6$ $\mu \mathrm{g} / \mathrm{ml}$. Mean serum Adiponectin levels in RA/OP patients with low bone mineral density were $52.42 \pm 0.69 \mu \mathrm{g} / \mathrm{ml}$. Adiponectin levels of $44 \mu \mathrm{g} / \mathrm{ml}$ and higher were 
associated with osteoporosis. Adiponectin levels of $43.9 \mu \mathrm{g} / \mathrm{ml}$ and lower were associated with normal bone density.

Conclusions: Thus, we revealed that Adiponectin levels depend on osteoporosis presence in RA patients. We suppose that Adiponectin determination may be useful laboratory marker for OP diagnosis.

\section{References:}

[1] Eliseev M.S. Revmatoidnyj artrit na Kongresse EULAR-2014 v Parizhe: novye zadachi, novye perspektivy. Revmatologija 2014;5(16):2-5.

[2] Polyakova Yu.V., Zavodovsky BV, Sivordova LE, Hakhverdyan Yu.R. Adipokiny with rheumatoid arthritis. International Scientific and Research Journal 2014;12(4):77-78.

Disclosure of Interest: None declared

DOI: 10.1136/annrheumdis-2017-eular.2360

\section{FRI0555 LEFT VENTRICULAR EJECTION FRACTION AND BONE MINERAL DENSITY AFTER CARDIAC TRANSPLANTATION}

L. Bautista Aguilar, A. Salmoral Chamizo, I. Gomez Gracia, R. Jimenez Gasco, P. Font Ugalde, E.C. Lopez Medina, M.L. Ladehesa Pineda, L. Perez Sanchez, A. Escudero Contreras, E. Collantes Estevez. Rheumatology, Reina Sofia University Hospital/IMIBIC/ University of Cordoba, Cordoba, Spain

Background: Left ventricular ejectionfraction (LVEF) has beendirectlyassociatedwith BMD in patientswithheartfailure. Nevertheless, no study has linked yet the left ventricular ejection fraction to bone mineral density and fragility fractures in cardiac transplantation.

Objectives: The main aim of this study was to evaluate the possible relationship between LVEF and BMD in heart transplantation and the association of LVEF with $25 \mathrm{OH}$ vitamin $\mathrm{D}$, paratohormone $(\mathrm{PTH})$ and markers of bone remodeling in patients with heart transplantation (osteocalcin, telopeptide $\mathrm{C}$ terminal (CTX).

Methods: Seventy nine patients (66 male) were included in this cross-sectional study with a mean age of $55,75 \pm 14,81$ years, body mass index (BMI) values of $26,95 \pm 5,35 \mathrm{~kg} / \mathrm{m}^{2}$ and an average post-transplantation period of $8,46 \pm 8,71$ years. Transthoracic doppler echocardiography measuring LVEF (\%) was calculated for each of patients, as well as bone mass study that included: bone mineral density scans of lumbar spine and hip, spine radiography, biomarkers of bone metabolism (calcium, phosphorus, osteocalcin,CTX,Parathyroid hormone and vitamin D). The association of LVEF with BMD and biomarkers of bone remodeling was determined by performing multiple linear regression analysis adjusted for variables directly related to BMD (age, sex, BMI, post-transplantation period and pharmacological treatment (daily corticoids dose, immunosuppressive treatment).

Results: A total of 79 patients were included in this present study. BMD in osteoporotic range was found in $31.2 \%$ of patients $(17.7 \%$ in spine, $16.52 \%$ in femoral neck and $13 \%$ in hip). Vitamin D deficiency ( $<20 \mathrm{ng} / \mathrm{d})$ was detected in $68.4 \%$ of patients. Vertebral fracture was found in $30.4 \%$ and a $2.6 \%$ hip fracture. Bivariate analysis showed that the group of patients with $\mathrm{FEVI} \leq 65 \%$ had a higher proportion of femoral neck osteoporosis $(p=0.04)$, higher proportion of osteoporosis in total hip $(p=0.03)$ and higher percentage of vertebral fractures $(p=0.04)$ compared with group with LVEF $>65 \%$.

The multiple linear regression analysis indicated that LVEF was independently associated with osteoporosis in spine $(B=-5.225, p=0.011)$, femoral neck osteoporosis $(B=-5.411, p=0.015)$ and vertebral fractures $(B=-5.433, p=0.002)$. In addition, LVEF was associated with osteocalcin levels $(B=-0.105, p=0.002)$. Conclusions: These results suggest that post-transplantation LVEF may have an influence on bone remodeling. However, further studies are neededin order to consider LVEF as a risk factor for osteoporosis and fractures due to fragility after heart transplantation.

Disclosure of Interest: None declared

DOI: 10.1136/annrheumdis-2017-eular.4434

\section{FRI0556 LONG-TERM EFFECTS OF BACK EXTENSOR STRENGTHENING EXERCISES ON QUALITY OF LIFE IN WOMEN WITH OSTEOPOROSIS}

S.A. Raeissadat ${ }^{1}$, A. Khalili ${ }^{2}$, L. Sedighipour ${ }^{3}$, M. Heidari Almasi ${ }^{4} .{ }^{1}$ Physical Medicine \& Rehabilitation Research Center, Modarres hospital; ${ }^{2}$ Department of Orthopedic Surgery, Department of Orthopedic Surgery; ${ }^{3}$ Physical Medicine \& Rehabilitation Research Center, Physical Medicine \& Rehabilitation Research Center; ${ }^{4}$ Boo-Ali hospital, Tehran, Iran, Islamic Republic Of

Background: A correlation exists between bone mineral density and physical activity level, suggesting that exercise may increase peak bone mass. Back extensor strength has been of major importance and had a strong effect on quality of life in this population.

Objectives: The aim of the present study was to evaluate the long-term effect of back extensor strengthening exercises on health-related quality of life (QOL) in women with osteoporosis.

Methods: In this randomized clinical trial, 183 women with osteoporosis were treated with pharmacotherapy and weight-bearing and balance-training exercises. The case group additionally performed back extensor exercises at home. Patients filled out the Persian version of the Short Form (SF-36) QOL questionnaire at baseline and 6 months post treatment.

Results: At the end, all physical and mental parameters of the SF-36 questionnaire improved significantly in the case group, except for one subscale of mental health, compared to the control group. In the control group, only some physical health dimensions (bodily pain, role limitation, physical function, vitality), and mental health status as a mental health subscale improved.

Conclusions: considering a major impact of back extensor exercises on improving QOL in women with osteoporosis over the long term, these exercises should be prescribed in routine management of these patients.

Disclosure of Interest: None declared

DOI: 10.1136/annrheumdis-2017-eular.1754

\section{FRI0557 DOES WEIGHTED KYPHO-ORTHOSIS (WKO) REDUCE RISK OF FALL IN WOMEN WITH OSTEOPOROSIS? A PRELIMINARY STUDY}

S.A. Raeissadat ${ }^{1}$, S.M. Rayegani ${ }^{2}$, L. Sedighipour $^{1}{ }^{1}$, M. Hashemi ${ }^{2}$,

M.H. Bahrami ${ }^{2}$. ${ }^{1}$ Physical Medicine \& Rehabilitation Research Center; ${ }^{2}$ Physical Medicine and Rehabilitation research center, Tehran, Iran, Islamic Republic Of

Background: It was suggested that posture training support with spinal orthosis including weighted kyphorthosis can improve balance in patients with osteoporosis.

Objectives: The aim of the present study was to determine the effects of weighted kyphorthosis on improving dynamic balance tests and consequently reducing risk of fall in women with osteoporosis.

Methods: In this Randomized controlled clinical trial, twenty three patients with osteoporosis were included. The patients were assigned into two groups: 1) control group who received 4-week home-based daily exercise program and 2) intervention group (weighted kyphorthosis) who performed exercises and wore weighted kyphorthosis for one hour twice a day. Patients were assessed using computerized balance tests by Balance Master (NeuroCom) (Limits of Stability, Step Quick Turn, Sit to Stand and Walk across tests) before and 4 weeks after start of treatment.

Results: Speed in walk across test was improved significantly in both groups compared to baseline from $(77.6 \pm 25 \mathrm{~cm} / \mathrm{s}$ to $91.57 \pm 30 \mathrm{~cm} / \mathrm{s}$ and from $72.60 \pm 20 \mathrm{~cm} / \mathrm{s}$ to $88.73 \pm 18 \mathrm{~cm} / \mathrm{s}$ ) in case and control groups respectively. Improvement in right turn time in step quick turn, end point excursion and mean of excursion parameters of Limits of Stability was more significant in orthosis group in comparison with control group $(\mathrm{P}<0.05)$.

Conclusions: Applying WKO together with exercise program improved some computerized balance tests in women with osteoporosis.WKO can be suggested as an effective intervention in postmenopausal women in order to reduce the risk of falling.

Key words: Osteoporosis, balance tests, Weighted KyphOrthoris, posture training support.

Disclosure of Interest: None declared

DOI: 10.1136/annrheumdis-2017-eular.1780

\section{FRI0558 PREDICTORS OF MORTALITY AND RE-FRACTURE AT 1 AND 3YEARS AFTER HIP FRACTURE}

L. Brites, M. Marques, A. Daniel, M. Santiago, A. Marques, J. Pereira da Silva Rheumatology department, Centro Hospitalar e Universitário de Coimbra, Coimbra, Portugal

Background: Osteoporosis is a major health problem, particularly in the elderly, because of fragility fractures and their consequences. Hip fractures (HF) are the most ominous in terms of morbi-mortality.

Objectives: The aim of our work was to establish the current mortality and re-fracture rate at 1 and 3 years after $\mathrm{HF}$, as well as their predictors.

Methods: The study included all patients aged $>40$ years, admitted to Coimbra University Hospital between May and October 2013 with the diagnosis of HF. Demographic and clinical data related to the fracture episode was collected from medical files. Patients or the caregiver were contacted to assess potential risk factors at baseline and major post-fracture events at 1 and 3 years after the index HF. The mortality and re-fracture rate 1 and 3 years after fracture were calculated. Possible predictor variables were tested by cox regression analysis: age, gender,

Table 1. Mortality and refracture predictors

\begin{tabular}{lccccc}
\hline & \multicolumn{2}{c}{ Mortality } & & \multicolumn{2}{c}{ Re-fracture } \\
\cline { 2 - 3 } & p-value & Exp (b) & & p-value & Exp (b) \\
\hline Gender & 0,106 & 2,052 & & 0,265 & 3,089 \\
Age & 0,002 & 1,075 & & 0,276 & 0,953 \\
Katz index & 0,116 & 1,154 & & 0,752 & 0,918 \\
Physiotherapy & 0,020 & 2,167 & & 0,499 & 0,638 \\
BMI & 0,812 & 0,991 & & 0,142 & 0,891 \\
Parent hip fracture & 0,015 & 0,355 & & 0,196 & 0,322 \\
Current smoking & 0,453 & 0,615 & & 0,394 & 0,417 \\
Corticotherapy & 0,013 & 0,404 & & 0,639 & 0,637 \\
Rheumatoid arthritis & 0,071 & 2,848 & & 0,798 & 1,410 \\
Secondary osteoporosis & 0,172 & 0,566 & & 0,154 & 0,321 \\
Alcohol intake & 0,037 & 0,370 & & 0,980 & 348544,658 \\
Charlson index & 0,000 & 1,384 & & 0,835 & 0,941 \\
Number of re-fractures & 0,660 & 0,781 & & & 0,430 \\
Anti-osteoporotic treatment & & & & & 0,474 \\
\hline
\end{tabular}

